\title{
Social Sciences, Complexity and Sociology of the Present in Edgar Morin
}

By Alex Galeno \& Fagner Torres de França Abstract- The article intends to revisit the contribution of the french thinker Edgar Morin (1921-) to the construction of a plural and open method of research in Social Sciences. We will have as theoretical-epistemological basis the sociology of the present, an approach of social phenomena developed by the author during three decades, from the 1940s to the 1970s, constituting the matrix of complex thinking. The present work defends the idea that the central categories of the present sociology, such as phenomenon, crisis and event, as well as the so-called living method of empirical research are still fundamental today in the sense of proposing an opening of the social sciences to phenomena increasingly more complex and multidimensional. This presupposes the researcher's subjective and objective engagement, narrative ability, and sensitivity to grasp revealing detail.

Keywords: edgar morin; sociology of the present; social sciences.

GJHSS-C Classification: FOR Code: 160899

Strictly as per the compliance and regulations of:

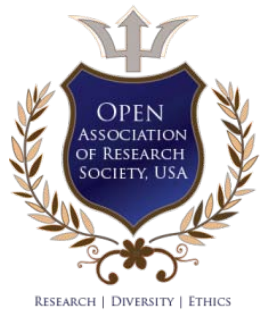

(C) 2019. Alex Galeno \& Fagner Torres de França. This is a research/review paper, distributed under the terms of the Creative Commons Attribution-Noncommercial 3.0 Unported License http://creativecommons.org/licenses/by-nc/3.0/), permitting all noncommercial use, distribution, and reproduction in any medium, provided the original work is properly cited. 


\title{
Social Sciences, Complexity and Sociology of the Present in Edgar Morin
}

\author{
Ciências Sociais, Complexidade e Sociologia do Presente em Edgar Morin
}

\author{
Alex Galeno ${ }^{\alpha}$ \& Fagner Torres de França ${ }^{\sigma}$
}

\begin{abstract}
The article intends to revisit the contribution of the french thinker Edgar Morin (1921-) to the construction of a plural and open method of research in Social Sciences. We will have as theoretical-epistemological basis the sociology of the present, an approach of social phenomena developed by the author during three decades, from the 1940s to the 1970s, constituting the matrix of complex thinking. The present work defends the idea that the central categories of the present sociology, such as phenomenon, crisis and event, as well as the so-called living method of empirical research are still fundamental today in the sense of proposing an opening of the social sciences to phenomena increasingly more complex and multidimensional. This presupposes the researcher's subjective and objective engagement, narrative ability, and sensitivity to grasp revealing detail.
\end{abstract}

Keywords: edgar morin; sociology of the present; social sciences.

Resumo- O artigo pretende revisitar a contribuição do pensador francês Edgar Morin (1921-) para a construção de um método plural e aberto de pesquisa em Ciências Sociais. Teremos por base teórico-epistemológica a sociologia do presente, via de aproximação e abordagem dos fenômenos sociais desenvolvida pelo autor durante três décadas, dos anos 1940 aos anos 1970, constituindo-se matriz do pensamento complexo. $O$ presente trabalho defende a ideia de que as categorias centrais da sociologia do presente, tais como fenômeno, crise e acontecimento, bem como o chamado método vivo de pesquisa empírica são ainda hoje fundamentais no sentido de propor uma abertura das ciências sociais para fenômenos cada vez mais complexos e multidimensionais. Isso pressupõe engajamento subjetivo e objetivo do pesquisador, capacidade narrativa e sensibilidade para captar o detalhe revelador.

Palavraschave: edgar morin; sociologia do presente; ciências sociais.

\section{INTRODUÇÃO}

r dgar Morin é um dos pensadores mais prolíficos dos séculos XX e XXI. Possui uma vasta produção intelectual que transita pela sociologia, antropologia, filosofia, comunicação, educação e estética. $\mathrm{O}$ desafio que sempre se colocou foi o de fugir

Author a: Geógrafo e professor da UFRN. Doutor em Ciências Sociais pela PUC/SP. Coordenador do Programa de Pós-Graduação em Ciências Sociais da UFRN. Autor de Antonin Artaud: a revolta de um anjo terrivel (SULINA, 2005). e-mail: alexgalenno@gmail.com Author o: Jornalista, mestre e doutor em Ciências Sociais pela UFRN. e-mail: fagnertf@yahoo.com.br a uma concepção disciplinar e fragmentada de ciência, desenvolvendo uma epistemologia de base complexa com o objetivo de articular as diversas áreas de conhecimento. Antes de delinear sua teoria da complexidade, a partir de meados da década de 1970, Morin aventurou-se pelo que chamou de sociologia do presente, embrião do pensamento complexo, no intuito de estabelecer comunicações entre as várias dimensões intrínsecas ao mundo da vida (econômicas, sociais, comunicacionais, demográficas, mitológicas).

Desde os anos 1940, quando inicia sua vida intelectual escrevendo para os jornais do Partido Comunista Francês (de onde seria expulso após a segunda-guerra), até hoje, embora tenha escrito sobre múltiplos temas, sua preocupação parece ter sido uma só: elaborar vias de abordagens da realidade capazes de enfrentar fenômenos sociais cada vez mais complexos e multidimensionais, para os quais o velho instrumental teórico da sociologia dominante mostravase crescentemente obsoleto, mais notadamente a partir dos acontecimentos de 1968 (TACUSSEL, 2002, MORIN, 2006). Nada mudou. Os fatos hoje continuam a desafiar o olhar muitas vezes atônito dos observadores sociais. Por isso faz-se necessário um retorno à sociologia do presente e à complexidade no sentido de propor uma concepção reformada de sociologia.

\section{Um Mestre da Indisciplina}

Edgar Morin nasceu em Paris no dia 8 de julho de 1921. Francês judeu de origem sefardita, formou-se em direito, história e geografia, mas dedicou a vida aos estudos em sociologia, antropologia, educação, filosofia e epistemologia. Devido ao trânsito constante entre os saberes disciplinares, contrabandeando ideias e borrando fronteiras, tornou-se um pensador de difícil classificação. Integrou as fileiras da resistência francesa contra a invasão alemã e no ano seguinte ao fim do conflito viaja ao país vizinho para escrever um livro de conjuntura, O ano zero da Alemanha (2009), publicado originalmente em 1946, seu primeiro trabalho nos marcos daquilo que posteriormente chamaria de sociologia do presente.

O estudo sobre a Alemanha não era de conteúdo antialemão ou revanchista. Pelo contrário, rejeitava a ideia de culpabilidade em benefício da noção de responsabilidade que o novo Estado alemão deveria 
assumir com a nação e o mundo no pós-guerra. Tratava-se de tentar entender como foi possível um país tão intelectualmente desenvolvido ter arrastado o mundo à determinada situação de horror e o que poderia ser feito no sentido de evitar tragédias futuras. Portanto, é um livro não apenas de diagnóstico, mas também de prognóstico, de acordo com os dois principais imperativos da sociologia do presente, quais sejam, interrogar um acontecimento imprevisível e constatar o que ele revela e inova.

Talvez motivado por suas incursões no mundo do jornalismo, aliadas a seu interesse por comunicação e sociologia, Morin tenha desenvolvido, primeiro intuitivamente, depois sistematicamente, um método de pesquisa dos fenômenos sociais cujo desafio era compreender e narrar um fato no calor do instante, mas para além dele. E não um fato qualquer, como no jornalismo cotidiano, mas um acontecimento no sentido forte do termo, de caráter modificador, que responde a uma crise e carrega a potência de uma outra possibilidade.

Foi assim com $O$ ano zero da Alemanha (2009) e outros ensaios, entre eles $O$ homem e a morte (1988), publicado em 1951; O cinema ou homem imaginário (1970), de 1956, que parte do cinema para chegar às raízes de uma antropologia fundamental; As estrelas: mito e sedução no cinema (1989), de 1957, relacionado mitos antigos e modernos; Crônica de um verão (1961), filme-manifesto escrito e dirigido em parceria com o cineasta e etnólogo francês Jean Rouch; Cultura de massa no século XX - Neurose (2011), volume 1, de 1962; Commune em France: la métamorphose de Plozévet (1967), seu mais completo e importante trabalho elaborado no registro da sociologia do presente, a partir de um estudo transdisciplinar sobre o processo de modernização em uma comunidade de pescadores; Maio de 68: a brecha (2018), redigido em parceria com os amigos Claude Lefort e Cornelius Castoriadis no mesmo ano de 1968; La rumeur d'Orléans (1969), sobre a circulação de um boato acerca de supostos crimes cometidos por comerciantes judeus contra mulheres francesas no interior de suas lojas; e, finalmente, Cultura de massas no século XX Necrose (2006), volume 2, concluído e publicado em 1975, uma espécie de balanço final da sociologia do presente, da cultura de massas e da crise cultural.

A partir da década de 1970 há no pensamento de Edgar Morin o que poderíamos chamar de uma virada epistemológica em direção a uma sociologia do conhecimento. Seu livro de 1973, intitulado 0 paradigma perdido: a natureza humana (1977) é um deslocamento acentuado em direção a uma epistemologia complexa das ciências sociais em detrimento de análises fenomenológicas mais factuais e com metodologias de pesquisa de campo bem delineadas. Com esse livro Morin anuncia a redação de seu projeto mais ambicioso, considerado sua obra máxima, O método, construído em seis volumes durante quase 30 anos, entre 1977 e 2004. É a culminância de um modelo de pesquisa transdisciplinar desenvolvido desde a sociologia do presente.

\section{ili. Pensador Das Margens e do Desvio}

Antes de explicitarmos as bases para uma ciência social complexa, urge o registro sobre a marginalidade presente nas referências sociológicas no Brasil e, particularmente, na França sobre a produção teórico-epistemológica de Morin. Roggero (2008, pag.192) chama a atenção sobre sua marginalização e falta de reconhecimento pela sociologia francesa. Diz ele: "Em um livro cujo objetivo é desvendar o lugar da sociologia francesa em 2000, vemos o nome de Edgar Morin citado apenas uma vez, restrito ao primeiro volume, quando quatro dos seis volumes definitivos já haviam sido escritos até aquela data". ${ }^{1}$ Tal realidade não se distingue da produção brasileira. Morin e a sua teoria da complexidade são ignorados pelos cientistas sociais. Basta observar as referências bibliográficas da área de ciências sociais, sobretudo na ANPOCS (Ver cadernos 2017-2018).

É preciso dizer que se as ciências sociais e, em especial a sociologia, ignoram Morin, por outro lado, há um reconhecimento importante em outras áreas. Destacadamente, em educação e comunicação. As obras A cabeça bem-feita (2000a), Os sete saberes necessários à educação do futuro (2000b) e Cultura de Massas no Século XX. Espírito do tempo. vol. 1 Neurose e vol. 2 - Necrose (2011a; 2006) são exemplos de sucessos editoriais absolutos no país nas referidas áreas. Mesmo que marginal nas ciências sociais no Brasil, não quer dizer que Morin não seja reconhecido. Desde os anos 1960 o autor vem ao país ${ }^{2}$ e seu pensamento tem se propagado através de grupos de pesquisa como GRECOM-UFRN, Complexus-PUC-SP e Instituto da Complexidade-RJ, nos quais se destaca o GRECOM. Há 25 anos o grupo tem no pensamento de

\footnotetext{
${ }^{1} \mathrm{O}$ autor se refere à obra de J.-M Berthelot (dir), La Sociologie française contemporaine. Paris: PUF, 2000, p. 125. Edgar Morin destaca em Meu Caminho (2010a) as querelas sociológicas francesas, sobretudo, advindas de Pierre Bourdieu: "A maioria dos sociólogos considerava-me um marginal, até mesmo um sujeito bizarro, mas não me atacavam. Por que Bourdieu fez isso? Talvez porque eu me parecia muito com ele e, simultaneamente, fosse muito diferente. Fomos considerados dois inimigos, dois rivais da sociologia. Não vivenciei as coisas assim. Minha existência lhe fazia muita sombra, mas sua existência não me incomodava; era sua animosidade que me fazia sofrer. (...) Certamente, ele tem sua teoria sociológica, em minha opinião unilateral, que triunfou durante algum tempo. Ele talvez tenha ampliado minha marginalidade, mas ela não tinha nenhuma necessidade do seu ataque; essencialmente, era decorrente do caráter de minha obra. Para mim, ser um sociólogo é ser capaz de pensar os fenômenos econômicos, sociais, psicológicos, culturais, religiosos e mitológicos em correlação e interação." (pag. 134).

${ }^{2}$ Cf. MORIN, Edgar. Meus demônios. Tradução de Leneide Duarte e Clarice Meireles. $5^{a}$ Ed. Rio de Janeiro: Bertrand Brasil, 2010b.
} 
Morin e nas chamadas ciências da complexidade suas principais referências ${ }^{3}$. Destaca-se ainda a realização do I Congresso Inter-Latino do Pensamento Complexo na Universidade Cândido Mendes-RJ em 1998. Não menos importante é o reconhecimento pelo SESC-SP à obra e vida de Morin. A instituição tem traduzido e publicado obras essenciais do autor, realizado simpósios e até mesmo lhe dedicado um site. ${ }^{4}$

Tal realidade nos revela a condição de um pensador marginal nas ciências sociais. Marginal pela singularidade da obra e escolhas éticas do autor por um lado e, por outro, pela força hegemônica de um tipo de ciência social produzido há décadas. Algumas passagens de sua trajetória são relevantes para melhor compreensão desta prática e condição de ação na marginália. Uma delas diz respeito a sua escolha de não fazer carreira profissional no mundo universitário, embora tenha recebido 27 títulos de Doutor Honoris Causa em universidades do mundo inteiro. Sua entrada no CNRS (1951) Ihe garantiu relativa autonomia como pesquisador e intelectual. Como revela em Meu caminho (2010a, p. 129),

(...) por sugestão de Georges Friedmann que eu conhecera em Toulouse e que dirigia o Centro de Estudos Sociológicos, no bulevar Arago, solicitei minha alocação na categoria de pesquisador no CNRS. Os pareceres favoráveis de Maurice Merleau-Ponty, Vladimir Jankélévitch e Pierre Georges ajudaram na aprovação de minha candidatura.

A natureza autônoma de Morin também já se revela antes. Primeiramente em 1946, quando publicou O ano zero da Alemanha (2009). Uma espécie de "sociodiagnóstico" de uma Alemanha arrasada no pósguerra. E como afirmamos antes, antecipa avant la lettre sua sociologia do presente. A segunda passagem que caracteriza sua autonomia como autor marginal é sua pesquisa sobre o fenômeno da morte, que resultou em O Homem e a Morte (1988). Morin expressa a ideia de uma antropologia complexa, isto é, uma antropologia capaz de religar concepções sociológicas, psicológicas, históricas e econômicas ao pensar a diversidade do humano e que, além disso, contemple a reflexão filosófica sobre a condição humana. Tal como o livro anterior, esta publicação parece antecipar a

\footnotetext{
${ }^{3}$ A UFRN e a cidade Natal, na qual já esteve por cinco vezes, têm sido generosas com o pensador francês. Além de the conceder o título de Doutor Honoris Causa, foi palco de uma das maiores acolhidas de público a um intelectual. No ano de 2010, Morin palestrou sobre $O$ destino da humanidade para aproximadamente oito mil pessoas na Praça Cívica da Universidade. Um dos eventos mais marcantes presenciado na instituição. As passagens de Edgar Morin pela UFRN e por Natal estão registradas em ALMEIDA, M. C; REIS, M. K. S.; FRANÇA, F. Edgar Morin: conferências na cidade do sol Natal/Brasil (1989 a 2012). Natal: EDUFRN, 2018.

${ }^{4}$ A ousadia política de Edgar Morin em realizar uma reforma do pensamento a partir de bases epistemológicas das ciências da complexidade tem se solidificado em outros lugares, tais como no Peru, Cuba, Colômbia, Argentina, Uruguai, México, Espanha, Portugal e Itália.
}

aventura de $O$ Método, dado o caráter transdisciplinar de investigação científica. Ainda em Meu caminho (2010a, p. 125) esclarece sua trajetória:

Eu ainda não havia incorporado as palavras 'método' e 'complexidade', mas sabia que era necessário ter uma visão poliscópica, múltipla, de meu tema. Eu queria conhecer as diferentes atitudes humanas diante da morte. Devorei obras de etnologia e antropologia, explorei todas as ciências humanas, as ciências da vida, as filosofias.

Noutra direção, constatamos a marginalidade por uma espécie de exílio cognitivo imposto ao pensamento moriniano a partir de um modelo de ciências sociais hegemônico. Em particular um pensamento sociológico que tem secundarizado as questões epistemológicas ou reflexivas em nome de um empiricismo pretensamente portador de objetividade científica. Em Sociologia (1998), ainda não traduzido no Brasil, o autor chama a atenção para a necessidade de uma "sociologia da sociologia" e para um "direito à reflexão". Isto é, uma disciplina que reflita sobre suas bases teóricas e objetos pesquisados a partir de uma dimensão multidimensional. Para isso, diz Morin, devese levar em conta "o duplo objeto da sociologia da sociologia."

Temos agora de abordar o duplo problema do objeto da sociologia. Com efeito: 1) O conhecimento sociológico é um conhecimento com uma pretensão ou alcance científico que, por conseguinte, deriva do conhecimento científico, o qual por sua vez deriva da sociologia do conhecimento (e assim por diante); 2) A sociologia é uma coisa particular nas suas atividades e instituições, que tenta englobar a sociedade no seu conhecimento (MORIN, 1998, pag. 36-37).

Assim, a tentativa sísifa moriniana é fazer com que o conhecimento sociológico mantenha uma soberania reflexiva diferenciando-se, portanto, de concepções teóricas que o percebem como resultante de determinações culturais, sociais e históricas. Concebido desta maneira, o conhecimento sociológico perde sua capacidade de autonomia reflexiva e, também, sua objetividade e capacidade inventiva para novas descobertas e novas verdades. Esta visão, obviamente, é herdeira do determinismo clássico e que continua fortemente influente a partir de pensamento contemporâneo. Assegura Morin que esse "É o ponto de vista que exprimem as concepções de Bloor ou Bourdieu, como as de uma vulgata marxista, que faz da ciência uma ideologia." (MORIN, 1998, pag. 37)

Ao não priorizar pensar ou conhecer sobre o conhecimento produzido e suas implicações metodológicas, a sociologia esvazia-se de pensamento. Concordando com Marx em sua terceira tese sobre Fuerbach, quando se perguntou sobre "quem educa os 
educadores" 5 , Edgar Morin tem se dedicado em suas obras a pensar sobre o conhecimento do conhecimento. Tal como Marx, tem se preocupado em uma reforma do pensamento, pois para ele as ideias se constituem em forças próprias imaginariamente e agem sobre as ações dos sujeitos e, em especial, dos pesquisadores e educadores. Por esta razão, a categoria do homem genérico de Marx (2010) sempre tem sido fundamento. Para Morin (2010c), a noção de homem-genérico não se relaciona apenas ao gênero humano, mas ao que é capaz de gerar aptidões a todas as características e às qualidades humanas que se manifestem na história. Relaciona-se, ainda, a inumeráveis outras virtualidades ainda não realizadas ou ao mundo do possível. Portanto, da ordem da multiplicidade e do inacabamento.

\section{O Direito À Reflexão}

Torna-se impossível a renovação da sociologia sem que ela priorize os pressupostos reflexivos e multidimensionais, anunciados anteriormente. Constatase, assim, a necessidade de que uma das tarefas de pensadores, professores e pesquisadores das ciências sociais é se colocarem questões cognitivas sobre questões de Método ${ }^{6}$.

Em L'aventure de La Methode (2015b), Morin resume sua trajetória reflexiva, investigações e descobertas a partir de quatro eixos fundamentais: 1.0 mundo físico, no qual advoga a necessidade de conceber o mundo não mais como parte de uma ordem determinista, mas, ao contrário, o concebe como a dialética ordem-desordem-organização como uma relação entre interações e retroações; 2. O mundo vivo, em que não faz sentido a disjunção do homem biológico do homem cultural e nem a separação entre cérebro e espírito; 3. A transdisciplinaridade, que torna possível a religação entre os mais diversos saberes rompendo, assim, com a fragmentação ou compartimentos disciplinares do pensamento; e 4. 0 conhecimento, que se constitui no eixo primordial das elaborações morinianas. Para este eixo confluem os outros e dão sustentação epistemológica para um conhecimento complexo e para um conhecimento pertinente. Em suas palavras,

A noção de complexidade começou a me possuir ao mesmo tempo como obstáculo e via de elucidação. A

\footnotetext{
5 "A doutrina materialista da transformação das circunstâncias e da educação esquece que as circunstâncias têm de ser transformadas pelos homens e que o próprio educador tem de ser educado". In: MARX, K; ENGELS, F. A ideologia Alemã - $1^{\circ}$ capítulo - seguido das Teses sobre Feuerbach. Tradução de Sílvio Donizete Chagas. São Paulo: Centauro, 2002, p. 108.

${ }^{6}$ Por esta razão, Morin publicou os seis volumes de 0 método: 1 . A natureza da natureza (2013); 2. A vida da Vida (2015a); 3. O conhecimento do conhecimento (2012a); 4. As ideias. Habitat: vida, costumes, organização (2011b); 5. A humanidade da humanidade. A identidade humana (2012b); 6. A ética (2011c).
}

palavra, extremamente difundida, trai, na linguagem corrente, uma lacuna cognitiva: a incapacidade de definir ou descrever um fenômeno ou um problema. Seria preciso conceber uma forma de pensar capaz de descrever e definir as complexidades percebidas. De fato, a palavra complexidade veio iluminar retrospectivamente minha forma de pensar, que já buscava religar os conhecimentos dispersos, enfrentar as contradições no lugar de as contornar, se esforçar por ultrapassar a alternativa entre opções julgadas inconciliáveis (MORIN, 2015b, P. 36-37, grifo do autor, tradução nossa).

Como ampliação da perspectiva epistemológica anunciada acima, é importante ressaltar que a literatura, também, sempre se fez presente na obra e vida de Morin. Em Meus Demônios (2010b), sobretudo, ele afirma que a literatura é antena para o mundo e vestimenta para a vida. Para ele, escritores como Dostoiévski, Balzac, Tolstói, Victor Hugo, Marcel Proust nos falam sobre a condição humana com radicalidade: a compaixão, o perdão, a justiça, a memória e a política são possíveis de abordagens pela literatura. Morin publicou dois romances Une Cornerie (1948) e L'île de Luna (2017) e um livro de poesias, Poésies du Métropolitain (2018). Além das incursões literárias, Morin mantém o hábito da publicação de diários, entre eles Diário da China (2007), Díario da Calífórnia (2012c), Chorar, Amar, Rir, Compreender (2012d), Um Ano Sísifo (2012e), além de Journal d'un livre (1981), Jounal 1962-1987 (2012f) e Journal 19922010 (2012g).

Os Diários são como hologramas que expressam totalidades a partir de fragmentos íntimos e singulares. Noutros termos, é como se as partes do indivíduo religassem a condição do homem genérico marxiano ou da própria condição humana. Aqui presenciamos o exercício do método vivo no qual vida e obra são tecidos e religados. De uma vez por todas Morin demonstra sua escolha ética e política quando mantém a vida intelectual como inseparável de sua própria vida. Ele como Nietszche ignora o que poderia ser considerado como "problemas puramente intelectuais". Por isso afirma em Meus Demônios (2010b, p. 9), "Não sou daqueles que têm uma carreira, mas dos que têm uma vida".

\section{O Sociólogo Legislador de Uma Sociologia do Presente}

Ousamos dizer que Morin expressa uma antropolítica e se aproxima da distinção que Nietzsche faz entre o Filósofo legislador e o Filósofo professor. Yannis Constantinidès (2000, p. 200), chama a atenção para esta flagrante oposição. Opondo-se à visão científica moderna de sua época, para o filósofo alemão, a filosofia era convocada a dominar pela especulação. Isso explica, de um lado, os filósofos se tornarem homens da ciência e não se dando conta dos 
atos e valores dominantes e, do outro lado, tornarem-se filósofos legisladores. Só eles, diz Nietzsche, merecem o título de filósofos.

Ora, se os filósofos devem ser os legisladores voltados para o devir e não simples professores de filosofia, é porque seus papéis não podem ser reduzidos a interpretação e a fixação de valores passados. Para Nietzsche,

Os fílósofos verdadeiros são aqueles que comandam e legislam: eles dizem 'será assim'! eles determinam em primeiro lugar o para onde? (Wohin) E para o que fazer? (Wozu) do homem e dispõe nesta ocasião do trabalho preparatório de todos trabalhadores filosóficos, de todos aqueles que se tornaram mestres do passado, - eles estendem uma mão criativa para se amparar no futuro e em tudo o que se coloca diante dele como meio, instrumento, martelo. Seu conhecer é criar, seu criar é legislar, sua vontade de verdade é - vontade de potência. (2005, fragmento 211, p. 105-106).

Por que tal digressão? Em razão de Morin se negar - como Nietzsche - a tornar-se um sociólogo ou filósofo professor. Ao contrário, Morin é um sociólogo legislador, pois se preocupa e se insere no movimento e na ordem do mundo. E um pensador legislador na medida em que advoga uma reforma do pensamento e sugere uma utopia concreta e uma politização do sujeito e do conhecimento. As proposições epistêmicas a partir de uma sociologia do presente são o substrato para os legisladores das ciências sociais. Evidentemente que se exige também a existência, sobretudo, de sociólogos legisladores.

A sociologia do presente teve seu ponto alto em meados da década de 1960. Em 1965, Morin instala-se em uma comunidade de pescadores na comuna de Plozévet, região da Bretanha, como coordenador de uma equipe multidisciplinar destacada pelo governo francês para investigar o processo de modernização da localidade. Inicialmente, a comuna havia sido subdividida segundo as disciplinas (sociologia, antropologia, psicologia, economia), ignorando o que se passava entre elas, ou seja, o essencial. Nessa pesquisa Morin refina e reafirma suas vias de abordagens para os fenômenos multidimensionais fazendo dialogar as áreas do conhecimento no sentido de construir uma compreensão mais ampla e articulada de uma modernização simultaneamente sociológica, antropológica, técnica, econômica e psicológica.

O empreendimento da sociologia do presente foi paulatinamente se diluindo, nos escritos de Morin, dentro do chamado pensamento complexo, elaboração de caráter mais teórico pela qual se torna mais conhecido. Ou melhor, foi-se imbricando com ele. O primeiro está contido no segundo. É quase, pode-se dizer, sua evolução necessária do concreto ao abstrato. Percebe-se claramente, em sua obra, uma linha de continuidade, um fio condutor alinhavando seus diversos livros e períodos. Ao estudar a guerra, a morte, o cinema, os meios de comunicação de massa, a economia do estrelato, as convulsões sociais, a política internacional ou a educação Morin, na verdade, está a procura de uma via de abordagem adequada para pensar sobre uma sociedade na qual fenômenos crescentemente complexos serão dificilmente compreendidos a partir de um paradigma disciplinar e fragmentador.

Com exceção de Bernard Paillard, pesquisador que esteve presente durante a experiência de Plozévet, a sociologia do presente não deixou herdeiros nem outras pesquisas conhecidas, não obstante seus marcos teóricos e procedimentos de investigação terem sido bem registrados, desenvolvidos e delineados pelo autor, especialmente em seu livro Sociologia (1998), cuja terceira parte é amplamente dedicada ao tema.

Justifica-se o resgate da sociologia do presente na medida em que ela permite elaborar uma teoria social de base complexa e multidimensional. Ao firmar as bases de uma metodologia de pesquisa mais ampla e atenta aos movimentos da sociedade, Morin tem em mente a oposição entre uma sociologia dominante, da especialização disciplinar e das regularidades estatísticas, e uma outra sociologia mais centrada na crise, no fenômeno minoritário e no acontecimento revelador, respeitando a ideia de Marx segundo a qual "a sociedade burguesa, pelo seu próprio desenvolvimento, gera as contradições que a minam, isto é, opera simultaneamente um duplo processo de autoprodução e de autodestruição" (Morin, 2006, p. 13). Mais do que isso, aceitando a ideia de multicausalidade dos fenômenos sociais, pois "o fenômeno é ao mesmo tempo, por exemplo, geográfico-histórico-econômicosociológico-psicológico-etc." (Morin, 1998, p. 165), assumindo assim um claro compromisso transdisciplinar.

A cegueira da razão acorda os monstros da tecnoburocracia do pensamento, responsáveis por um mundo no qual prevalecem dados, números, estatísticas e abstrações em detrimento das necessidades concretas de uma sociedade viva, referentes à moradia, saúde, educação, alimentação, cultura e lazer. A complexidade, como afirma Morin (2011c), não é a antítese do simples, mas guarda relação com a tessitura simultaneamente heterogênea e inseparável do social, recolocando o paradoxo do uno e do múltiplo, da unidade na diversidade. As ciências constroem (cada vez mais) zonas de especialização do conhecimento no sentido de organizarem os saberes e desambiguizarem o real, rechaçando a desordem e a incerteza, clarificando, distinguindo e hierarquizando ideias. O isolamento artificial dos âmbitos da vida resulta na racionalização do saber, ou seja, o fechamento da racionalidade. A sociologia do presente procura ser antídoto contra a fragmentação disciplinar. 
Vi. Fenômeno, Acontecimento, Crise: Categorias para uma Sociologia DO PRESENTE

O fenômeno, diz Morin (1998, p. 165), é algo que emerge na realidade social como um dado relativamente isolável - embora repleto de atravessamentos econômicos, históricos, culturais e sociais - objetivado em uma instituição, uma cidade, uma corrente de opinião, um mito, uma moda, dentre outras manifestações. A sociologia do presente é também uma sociologia fenomenológica. Tanto $O$ ano zero da Alemanha (2009) quanto La rumeur d'Orléans (1969), por exemplo, tratam das consequências sociais de dois dispositivos mitológicos que marcaram forte e tragicamente a história do século XX: os mitos da superioridade da raça ariana e do judeu como bode expiatório dos males do mundo.

Edgar Morin tinha 25 anos quando percorreu os escombros de uma Alemanha devastada pela guerra, em 1946, para ver in loco o que acabara de ocorrer. Chegou, a bordo de um avião militar, armado apenas de papel, caneta e duas ou três perguntas guia. Observou, tomou notas, questionou, vasculhou e reuniu material suficiente para escrever sua primeira reportagem sociológica de fôlego, depois publicada como O ano zero da Alemanha (2009). Encontrou Berlin ainda com o cano fumegante, a ponto de haver, diz ele, "recolhido no interior da chancelaria de Hitler, no meio dos documentos espalhados pelo chão, cartas assinadas de próprio punho pelo Führer atribuindo condecorações a soldados alemães e de ter contemplado a agonia de seu bunker" (MORIN, 2009, p. 14). Era preciso adentrar as ruínas, conversar com a população, conhecer nazistas, não nazistas, forças aliadas, caminhar pela cidade, pesquisar, investigar, sentir no vento a densa névoa de chumbo que encobria a história. Mas, acima de tudo, era preciso relatar.

Acerca do mito do líder messiânico, o autor observa que, "Como fenômeno ideológico coletivo, no nazismo ocorreu a irrupção do religioso e do místico na vida política, social e econômica, uma irrupção das mais primitivas da mais supersticiosa das religiosidades" (MORIN, 2009, p. 29), em associação com um cientificismo (o mito da raça pura) igualmente delirante. Em um conjunto de entrevistas com homens e mulheres de Berlin, de todas as idades e estratos sociais, Morin constata que, às vezes mais, às vezes menos, mas "De todas as formas, e qualquer que seja o caso, a noção de raça implica sempre um julgamento de valor" (p. 54), para o bem ou para o mal. Estes e outros mitos permearam o imaginário alemão antes e após a guerra.

23 anos depois, já com 48 anos e mais de duas décadas de experiência acumulada em pesquisa, tendo desenvolvido e consolidado seu método sociológico, Morin e uma equipe multidisciplinar composta por outros cinco pesquisadores franceses desembarca na cidade de Orléans, cerca de $110 \mathrm{~km}$ ao sudoeste de Paris, para sua última aventura na sociologia do presente, financiada pela comunidade judaica local. Um boato estava tirando o sono da população. O motivo: uma fantasmagórica ameaça sexual que, de repente, em apenas alguns dias, fez (res)surgir fortemente na cidade o espectro do antissemitismo. Mulheres brancas estavam desaparecendo dos provadores de roupas em seis lojas pertencentes a judeus. Eram atacadas com uma seringa contendo sedativo e transportadas com destino ao mercado de prostituição estrangeiro em país desconhecido.

Um pânico medieval acomete milhares de moradores locais sem que a polícia ou a imprensa tenha recebido uma única denúncia sequer. Trata-se de um boato em estado puro, pois nenhum desaparecimento foi registrado e não houve interferência dos jornais para a proliferação das informações. O rumor, de origem ancestral, era na verdade uma combinação de duas temáticas distintas, envolvendo tráfico de mulheres e aversão aos judeus. Tal associação constituiu, segundo conclusão de Morin (1969) após intensa investigação, um dispositivo mitológico de dupla face cujo desenvolvimento transformou as latências antissemíticas arcaicas em virulência.

A isso Morin chamou de "idade média moderna" (1969, p. 10), ou seja, há algo de arcaico que persiste naquilo que aparenta ser o verniz mais sofisticado de nossas relações sociais; mas também de moderno, pois ambas as temáticas (escravidão sexual e antissemitismo) habitam e seduzem o imaginário social há séculos, reaparecendo de tempos em tempos, com novas roupagens, graças também à mídia de massa e ao processo de modernização. Não por acaso o mito é transportado para o cenário dos grandes magazines, que marcam uma virada no estilo de vida, no comportamento e nos valores de emancipação do universo feminino no contexto da cidade moderna (MORIN, 1969, p. 57 et seq).

Portanto, o nazismo e o boato de Orléans são fenômenos mobilizados também pela categoria do acontecimento, entendida, antes de tudo, como uma informação que irrompe tanto no sistema social, intervindo de maneira múltipla e decisiva na história humana (uma catástrofe climática, uma invasão estrangeira, um golpe de estado, a irrupção de uma revolta, um aparentemente simples boato), quanto no sistema mental do sociólogo (reorientando seu esquema cognitivo) ${ }^{7}$. O acontecimento torna possível

\footnotetext{
${ }^{7}$ Como fica claro na seguinte afirmação, em Cultura de massas no século XX: vol. 2. Necrose: "Da mesma maneira que a sociedade de que ela era o olhar (o espelho?), a sociologia foi atingida pelo Maio de
} 
abordar o problema primordial da mudança para além da realidade social dos sistemas equilibrados, que

devem ser concebidos, segundo a expressão de Max Weber, como 'racionalizações utópicas', instrumentos cômodos que não se devem considerar como 'modelos verdadeiros' da realidade social: esta é, antes de mais, funcional-disfuncional em relação a estes pseudomodelos. É constituída por uma dialética permanente entre as tendências para a constituição de sistemas equilibrados e as contratendências desequilibradoras (MORIN, 1998, p. 166).

A sociologia do presente configura-se, assim, em uma sociologia dos acontecimentos (ou ciência do acontecimento) e uma ciência do devir (MORIN, 2014), na medida em que está atenta aos fenômenos minoritários capazes de apontar e/ou promover reorganizações sociais. A noção de acontecimento designa, portanto, o que é da ordem do "improvável, acidental, aleatório, singular, concreto, histórico" (ld., p. 250). Abrange ainda os circuitos comunicacionais, dentro dos quais se processam os acontecimentos, como demonstra o caso de Orléans ou das narrativas míticas acerca do salvador messiânico. Em Sociologia (1998), Morin faz referência aos acontecimentos-choque como aqueles que, diferentemente de um boato de circulação restrita, por exemplo, irrompem fortemente, de forma generalizada e, hoje em dia, quase imediata no universo imaginário de uma comunidade simbólica cada vez mais ampla.

O assassinato do presidente dos Estados Unidos da América John Fitzgerald Kennedy, em 22 de novembro de 1963, foi um destes acontecimentos que chocaram o mundo, uma "teletragédia planetária" (MORIN, 1998, p. 312 et seq.) vivida quase simultaneamente por todo o planeta, captada por milhares de testemunhas oculares da história. "A televisão apanhou o acontecimento com um pouco mais de uma hora de atraso sobre o assassínio. Agarrou-o quase de imediato, nunca mais largando o acontecimento" (p. 312). E, por meio da internet, podemos revivê-lo a qualquer momento. Em Cultura de massas no século XX: vol. 2. Necrose (2006), Morin fará referência ao acontecimento-informação (p. 28), cujo princípio é ser desestruturante.

Fenômeno e acontecimento se encontram, pois Morin (1998) procura observar o assassinato de Kennedy em seu caráter multidimensional e transdisciplinar, a partir de seus vários ângulos, tentando isolar relativa e arbitrariamente alguns vetores considerados mais importantes. Primeiro, a comoção. A morte de Kennedy foi um golpe no tecido político e vital dos EUA e além. Calou fundo no coração de milhões de pessoas, compatriotas ou não. Uma tragédia ao

68 em plena expansão, crescimento, desenvolvimento" (MORIN, 2006, p. 23), deparando-se com seus limites metodológicos e explicativos. mesmo tempo infra-política, extra-política e suprapolítica. Segundo, mergulhou da vida real para as cavernas do romance policial, despertando ainda hoje curiosidades acerca de teorias conspiratórias. Terceiro, sua telepresença. JFK detinha não apenas o cargo de líder máximo da maior potencial econômica mundial, mas era também um verdadeiro olimpiano, figura de destaque do star system. Havia algo de mitológico em sua imagem de felicidade, sempre em evidência: como primeiro presidente "jovem, belo, aberto, simpático; como o feliz esposo de uma bela cover-presidente; como o pai feliz de uns filhos belos e espertos" (p. 313). Kennedy e sua família não saiam dos noticiários.

Por fim, a sociologia do presente é também uma sociologia da crise, a ponto de Morin (1998) ter desenvolvido de forma embrionária uma espécie de crisiologia ou teoria da crise. Fenômeno, acontecimento e crise são noções recursivas, inseparáveis, imantadas. Para uma sociologia não preocupada em concentrar todos os seus recursos nas médias estatísticas ou nas amostras representativas, as crises constituem fonte de extrema riqueza. Crises são placas tectônicas subterrâneas cujo atrito provoca as movimentações na superfície. A parte invisível só pode ser acessada adequadamente por meio de estudo aprofundado. Nas cinco entradas feitas por Morin (2006) para apresentar a noção de crise, vale a pena destacar a última (letra e), na medida em que traz um bom resumo da ideia:

a crise reúne, de modo turvo e perturbador, repulsivo e atraente, o caráter acidental (contingente, circunstancial), o caráter de necessidade (ativando as realidade mais profundas, as menos conscientes, as mais determinantes) e o caráter conflitual. É aqui que entramos necessariamente em oposição a uma sociologia mecanística, normalizadora, que eliminaria a perturbação e o desequilíbrio (p. 29, grifo do autor).

A crise é o magma, a lava, o subsolo, o subjacente, a infraestutura, o latente, o inconsciente. Ainda em Maio de 68, em meio ao fogo cruzado, participando corpo a corpo nos acontecimento trepidantes (correndo o sério risco de elaborar interpretações apressadas e equivocadas acerca dos eventos), Morin (2014) redigiu uma série de artigos para - Le Monde sobre as revoltas que mobilizaram estudantes e operários franceses em barricadas pelas ruas do país há meio século. No mesmo ano os artigos foram publicados no livro Maio de 68: a brecha (2018), em parceria com Claude Lefort e Cornelius Castoriadis, até hoje uma das contribuições mais originais para aquele momento decisivo na história mundial.

Maio de 68 é uma ocasião privilegiada não apenas para compreender as transformações do espírito do tempo, mas um momento fecundo para questionar o próprio fazer sociológico. Segundo Morin (2018), durante os eventos dois tipos de interpretação se digladiam. A primeira, herdeira de uma tradição clássica, afeita aos dados, amostragens e 
questionários. E uma outra que tenta pensar não a partir das regularidades estatísticas e limites disciplinares, mas de situações extremas que podem desempenhar papel revelador de uma profunda crise social. Morin (2006) acredita que a sociologia dominante não estava apta a apreender a crise de Maio, e por isso precisava se reinventar. De fato, diz ele,

Só se pode compreender Maio de 1968 se levarem em consideração outras técnicas de pesquisa que não o questionário por amostragem que domina (dominava?) a sociologia e que, incapaz de cavar por baixo da crosta superficial das opiniões, era incapaz de prever o que estava latente ou brotava, ou de ver e conceber os dinamismos e as rupturas. Só se pode compreender o Maio de 1968 se se procura ficar acima e além do saber disciplinar parcelado, tentando reunir um corpo teórico de hipóteses para abarcar e estruturar o fenômeno. [...] a atenção dedicada ao fenômeno, ao acontecimento, à crise conduz não ao enfraquecimento, mas ao reforço da exigência teórica (2006, p. 25-26, grifo nosso).

Em outras palavras, tratava-se de elaborar uma interpretação em profundidade de uma crise a partir do estudo do fenômeno desencadeado pelo acontecimento. O que ele revela para além da produção apressada de números e opiniões nem sempre refletidas? Fundamentalmente, ontem como hoje, é preciso romper com as interpretações binárias e os modelos simplificadores de pensamento capazes de interditar a complexidade mesma do movimento da sociedade.

Em sua multidimensionalidade, Maio de 68 é o resultado complexo, ambíguo e heterogêneo, integrador e desintegrador, arcaico e anunciador, de uma crise ao mesmo tempo política, de valores, de um modelo de organização social questionado em grande parte pela ascensão de uma nova classe etária adolescente que surge no espaço público a partir da década de 1960, na esteira da proliferação da cultura de massas e de uma sociedade de consumo voltada ao crescimento, mas cujo ideal de felicidade entrava em crise de legitimação. Uma sociologia do presente necessita preservar, enfrentar, articular e operacionalizar as três categorias vistas acima. Não é uma confirmação a posteriori das teorias colocadas a priori. Pelo contrário, é preciso estar aberto à informação, vista como o elemento desorganizador de uma determinada realidade, portanto, capaz de furar os esquemas explicativo prédefinidos. "O mais importante é o mais surpreendente e paradoxal, aquilo que dificilmente é explicável com os conceitos de que dispomos" (MORIN; LEFORT; CASTORIADIS, 2018, p. 217), diz o autor. É no sentido de seguir de perto os fenômenos sociais de ordem complexa que Morin elaborou, além das categorias acima elencadas, vias de abordagem metodológicas chamadas por ele de método in vivo - ou simplesmente método vivo.

\section{Vil. Sobre o Método Vivo}

Em 1960 Edgar Morin realiza uma experiência radicalmente inovadora de sociologia do presente por se propor a fazê-la por meio do cinema. Crônica de um verão (1961), realizado em parceria com Jean Rouch, funda uma discursividade cinematográfica chamada pelos seus idealizadores de cinema-verdade, um cinema capaz de percorrer fenômenos, provocar acontecimentos e revelar crises. O filme é uma forma de experimentar empiricamente os princípios e vias de abordagens da realidade norteadores de seu método de pesquisa sociológico. Mesmo tendo escrito anteriormente outros livros nos marcos de uma sociologia do presente, esta é a segunda vez (a outra foi na Alemanha, em 1946) que Morin vai a campo aplicar suas técnicas de pesquisa.

No que consiste o método vivo?

Trata-se de um método de investigação capaz de favorecer a emergência dos dados concretos e a apreensão das diversas dimensões do fenômeno estudado recorrendo a diferentes tipos de abordagens, como pesquisa documental, observação fenomenográfica, anotações, registro de discussões, entrevistas, questionários, construção de narrativas e participação em atividades de grupos, chamadas de "práxis social" (MORIN, 1998, p. 171-172). Crônica de um verão (1961) exemplifica um tipo de abordagem flexível, adequada para os propósitos do autor, privilegiando a entrevista e a participação nas atividades dos grupos, enquanto $O$ ano zero da Alemanha (2009) enfatiza as anotações, observações e pesquisa documental.

A abertura para múltiplas estratégias de pesquisa está no cerne tanto da sociologia do presente quanto do método complexo, elaborado posteriormente. Exige rigor científico (diferente de rigidez), arte e capacidade de invenção e narração. Nas palavras de Maria da Conceição de Almeida, criar vias de abordagens

é o que se espera do sujeito sensível à complexidade do
tema ou fenômeno que quer conhecer, com o qual quer
dialogar. Aqui, certamente, o pesquisador abre mão dos
cardápios de receitas oferecidos pelos manuais de
pesquisa para criar suas próprias estratégias de
abordagem, seus operadores cognitivos. Produzir um
conhecimento pertinente é o que se espera dele:
relacionar o fragmento e o contexto, o local e o global é a
arte esperada das pesquisas multidimensionais e
complexas (2012, p. 115, grifo nosso).

Enfatizemos três passos multidimensionais para o desenvolvimento do método vivo, começando pela observação fenomenográfica. A observação fenomenográfica exige do sujeito sensível da pesquisa um olhar ao mesmo tempo panorâmico e analítico, 
particular e universal, capaz de contextualizar a informação e integrá-la ao todo do universo pesquisado. Por isso o pesquisador deve atuar por vezes como Balzac, em sua descrição enciclopédica da realidade, por vezes como Stendhal, atento ao detalhe significativo, estratégias narrativas fundamentais que devem ser exercitadas para ativar o "sentido perceptivo", atualmente "tão atrofiado nos sociólogos que se fiam no questionário, no gravador ou, pelo contrário, na simples especulação, que é preciso aprender a ver os rostos, os gestos, as roupas, os objetos, as paisagens, as casas, os caminhos" (MORIN, 1998, p. 172). Junte-se a isso uma cuidadosa elaboração de anotações, registros de discussões, impressões e cadernos de campo. Mais da metade do livro La rumeur d'Orléans (MORIN, 1969) é dedicada a reproduzir os diários pessoais dos pesquisadores e documentos coletados durante 0 processo de investigação.

O segundo passo multidimensional fundamental para a pesquisa são as entrevistas. Sumariamente falando, uma entrevista é caracterizada como uma comunicação pessoal para fins informativos. Mas há algo nesse processo mais importante que a informação, a saber, o fenômeno psicoafetivo constituído pela própria comunicação, na medida em que a palavra constitui-se na fonte mais duvidosa e ao mesmo tempo mais rica de todas. Tal fenômeno pode suscitar pequenos acontecimentos comunicacionais capazes de provocar modificações e revelações fundamentais no decorrer da pesquisa. É nesse sentido que, dentre os tipos possíveis de entrevistas, a sociologia do presente privilegia a entrevista não diretiva (MORIN, 1998).

Em geral, uma pessoa entrevistada orienta-se por dois desejos em conflito: expressar-se e ao mesmo tempo proteger-se. O objetivo da entrevista não diretiva é "quebrar o sistema de defesa do sujeito pela necessidade de se exprimir do próprio sujeito" (MORIN, 1998, p. 188, grifo do autor). Isso depende da relação de confiança mútua que o pesquisador necessita estabelecer com o entrevistado, além "da disciplina do entrevistador relativa ao não-comentário e à nãointervenção, da disponibilidade empática" (p. 188), princípios tão ausentes na sociologia quanto no jornalismo.

Daí a importância da criação de vínculos entre uns e outros. Por esse motivo, tanto em 1965, no caso de Plozévet, quanto em 1969, em Orléans, a exigência de Morin para que a equipe se instale nas regiões pesquisadas, se possível, na casa dos próprios moradores, participando da dinâmica local. Bernard Paillard, parceiro de Morin nos dois momentos fundamentais da sociologia do presente, narra sua experiência em Plozévet, no pequeno vilarejo de Kermeuguy. Diz ele: "participava da vida local e, por vezes, do trabalho de campo, vivia na companhia dos jovens, freqüentava os espaços de sociabilidade $\mathrm{e}$ hospedava-me na casa de um dos moradores" (PAILLARD, 2008, p. 24).

Crônica de um verão (1961) segue a mesma proposta, um filme construído quase que totalmente por meio de entrevistas não diretivas. A partir de uma pergunta-tema ("você é feliz?") feita aleatoriamente aos transeuntes nas ruas de Paris, os autores passam a estruturar um núcleo menor de participantes no intuito de aprofundar as questões suscitadas pelas respostas. Há nesse filme, diz Morin (2010), a busca de uma comunicação errática e oblíqua. Buscar alguma coisa exige método, saber o que, onde e como procurar. Por isso não se trata de um diálogo livre, entregue à improvisação da conversa. Exige destreza e certa objetividade do entrevistador para lidar com as subjetividades em erupção.

O núcleo do filme cristaliza-se porque as questões que cada um de seus participantes suscita não estão relacionadas simplesmente ao excepcional particular, ao raro e episódico, mas são a manifestação, no plano individual, de problemas profundos e gerais: "os do trabalho alienado, da dificuldade de viver, da solidão e da busca de uma fé" (MORIN, 2010a, p. 161). E isso levanta o difícil problema da verdade, pois o próprio caráter da palavra é movediço. A sociologia do presente deve incorporar uma vocação simultaneamente científica e ensaística. Deve propor uma narrativa capaz de apontar caminhos possíveis para a interpretação de um fenômeno social. Portanto, é uma sociologia capaz de assumir a dimensão de incompletude e inacabamento da realidade. Em Crônica de um verão (1961) a verdade é sempre provisória. Trata-se de uma verdade possível, que relaciona cada narrativa singular com o drama compartilhado pela experiência do grupo.

O terceiro passo multidimensional importante para uma sociologia do presente consiste em articular uma dinâmica de trabalho envolvendo não apenas os indivíduos, mas também os grupos, um processo denominado por Morin de "praxis social", isto é, tornarse atento "à realidade e à ação dos grupos sociais" (MORIN, 1998, p. 174). Ao exigir do pesquisador um olhar que transita entre o geral e o particular, solicitando uma visão ao mesmo tempo panorâmica e analítica, a sociologia do presente, afirma Almeida (2012, p. 113), desativa a oposição clássica entre micro e macropesquisas.

Nesse sentido, Morin (1998) procura localizar o indivíduo em um grupo e um grupo entre outros grupos. Em suas palavras, com a sociologia do presente,

Pudemos apreender os grupos não só de maneira indireta (através dos meios de investigação acima citados) mas também diretamente, quando era possível, ao nível das associações profissionais, políticas, ideológicas, confessionais e outras. Esforçamo-nos por situar estes agrupamentos em relação às classes sociais 
e às classes etárias. Tentamos ver os conflitos e tensões determinados pela sua vida ativa (p. 174).

$\mathrm{Na}$ investigação sobre Plozévet pode-se observar claramente o movimento pendular que oscila entre o macro e a micro, Balzac e Stendhal, a ciência e o ensaio, o rigor investigativo e a criação narrativa. La métamorphose de Plozevet (1967) inicia com uma descrição quase poética da região de Plozévet, sua paisageme geografia, passa pelo estudo da personalidade do habitante local, estende-se para a formação dos grupos (pescadores e industriários, jovens e velhos, mulheres e homens, partidários da esquerda e da direita) até chegar ao processo de modernização, tema central da pesquisa. Lá, diz Morin, "encontrei os traços de uma grandiosa luta entre dois mundos, encontrei as grandes correntes do tempo, os grandes problemas do homem, mas sempre encarnados nos rostos, nos olhares e nos destinos insubstituíveis" (1967, p. 12-13, tradução nossa).

A praxis social prevê também não apenas a observação, mas a participação e mesmo a intervenção em atividades dos grupos. Tal método de participação e intervenção foi utilizado, de modo semelhante, tanto em Plozévet quanto em Crônica de um verão (1961). Neste último caso em particular, faz parte da sequência final do filme a exibição, seguida de debate, das atuações dos personagens para eles próprios, debate que integra a versão final de película. A situação provocada gera desentendimentos e acusações, em geral acerca da falsa imagem apresentada por uns e outros, mas também entendimentos e empatias. No próprio processo de condução dos diálogos durante as filmagens, a participação dos diretores em cena (com o objetivo de marcar a ideia da intervenção) é constante.

Eis os princípios da intervenção-pesquisa:

1) O princípio da maiêutica social. Somos incitados a intervir quando cremos detectar uma situação "grávida" de mudança ou de inovação;

2) O princípio não diretivo. A nossa intervenção deve ser catalítica. Pode desencadear, mas não pode fixar, as normas e o programa de um movimento. Pode ajudar, não pode orientar;

3) O princípio de orientação selvagem (situaçõesteste ou para-experimentais);

4) O princípio de socratismo psicossociológico. A intervenção deve levar os interessados a interrogar-se sobre os seus problemas principais;

5) O princípio de utilidade comum aos pesquisadores e aos pesquisados (deontologia da troca) (MORIN, 1998, p. 175, grifo nosso).

Por fim, a praxis social está atenta às dinâmicas de trabalho estabelecidas entre os próprios pesquisadores, consubstanciadas no que 0 autor classifica de "autodesenvolvimento progressivo do sistema de interpretação" (1967, p.8), por meio das confrontações entre os dados dos pesquisadores e trocas dos diários de pesquisa redigidos por cada um, permitindo a autorregulação do grupo e a autocorreção das estratégias investigativas. Morin escreve, em La rumeur d'Orléans (1969, p. 13), que "Se nosso trabalho de campo foi tão fecundo em um tempo extraordinariamente curto, isso se deve à intercomunicação incessante das descobertas e à discussão quase permanente". Trata-se, portanto, de um intenso processo de intercomunicação, autocrítica, avaliação permanente e participação afetiva capaz de coordenar e otimizar os trabalhos da equipe.

\section{Vili. Conclusão}

O objetivo da sociologia do presente é problematizar as ciências sociais a partir de uma reforma do pensamento sociológico, capaz de associar uma cientificidade não mutilante, fechada e disciplinar atenta não apenas às médias e regularidades estatísticas, mas aberta também aos acontecimentos e aos fenômenos minoritários reveladores de tendências-, a uma possibilidade de conhecimento não estritamente científico. Importa restabelecer comunicações e articulações tanto com as outras ciências humanas quanto com a arte.

Trata-se, portanto, de pensar um outro sujeito de pesquisa cujo saber e formação possam aliar explicação (como aquele que permite a um sujeito conhecer um objeto enquanto objeto) e compreensão (sendo tudo o que permite conhecer um sujeito enquanto sujeito). Nesse sentido, é imprescindível abrir o pensamento sociológico sobre a literatura. O romance é um modo de conhecimento com potencial de retotalizar o universal a partir do singular concreto. Morin (1998) propõe que o conhecimento sociológico não se resume ao conhecimento científico stricto sensu, mas integra múltiplos modos cognitivos.

Nesse sentido, o sociólogo deve pensar-se para além do profissional habilitado a manejar um instrumental teórico-científico impessoal e anônimo capaz de revelar o que se esconde por traz das aparências dos comportamentos sociais, mas deve colocar-se também como autor, ou seja, um sujeito implicado na pesquisa que desenvolve um pensamento singular e uma narrativa pessoal sobre determinado tema, mobilizando sua consciência e sua reflexão de humano e cidadão.

\section{References Références Referencias}

1. ALMEIDA, Maria da Conceição de. Método complexo e desafios da pesquisa. In: ALMEIDA, Maria da Conceição de; CARVALHO, Edgard de Assis. Cultura e pensamento complexo. Porto Alegre: Sulina, 2012.

2. ALMEIDA, M. C; REIS, M. K. S.; FRANÇA, F. Edgar Morin: conferências na cidade do sol - Natal/Brasil (1989 a 2012). Natal: EDUFRN, 2018. 
3. CONSTANTINIDÈS, Yannis. Nietzsche legislateur. In: BALAUDE, J-F; WOTLING, Patrick (Orgs.). Lectures de Nietzsche. Paris, LGF, 2000.

4. CRÔNICA de um verão. Direção: Edgar Morin e Jean Rouch. Produção: Anatole Dauman. Roteiro: Jean Rouch. Música: Pierre Barbaud. Rio de Janeiro: Coleção Videofilmes, 2008. 1 DVD (85 min). $P$ \& B.

5. MARX, Karl. Manuscritos econômico-filosóficos. Tradução, apresentação e notas Jesus Ranieri. São Paulo: Boitempo, 2010.

6. MARX, Karl; ENGELS, Friedrich. A ideologia Alemã - $1^{\circ}$ capítulo - seguido das Teses sobre Feuerbach. Tradução de Sílvio Donizete Chagas. São Paulo: Centauro, 2002, p. 108.

7. MORIN, Edgar. Une cornerie. Paris: Nagel, 1948.

8. MORIN, Edgar. Commune em France. La Métamorphose de Plozevet. Ed. Fayard. 1967.

9. MORIN, Edgar. La Rumeur d'Orléans, Le Seuil, Paris, 1969.

10. MORIN, Edgar. O cinema ou o homem imaginário. Ensaio de antropologia sociológica. Tradução António Pedro-Vasconcelos. Lisboa: Moraes editores, 1970.

11. MORIN, Edgar. O paradigma perdido. A natureza humana. $5^{\text {a }}$ Ed. Lisboa: Publicações EuropaAmérica, 1977.

12. MORIN, Edgar. Journal d'un livre. Paris: Edsud, 1981.

13. MORIN, Edgar. O Homem e a Morte. EuropaAmérica. Portugal, s/d, 1988.

14. MORIN, Edgar. As estrelas: mito e sedução no cinema. Tradução de Luciano Trigo. $3^{a}$ ed. RJ: José Olympio, 1989.

15. MORIN, Edgar. Sociologia. Tradução de Maria Gabriela de Bragança e Maria da Conceição Coelho. Lisboa: Publicações Europa-América, 1998.

16. MORIN, Edgar. A cabeça bem-feita. Repensar a reforma, reformar o pensamento. Trad. Eloá Jacobina. Rio de Janeiro: Bertrand Brasil, 2000a.

17. MORIN, Edgar. Os sete saberes necessários à educação do futuro. Trad. Catarina Eleonora F. da Silva e Jeanne Sawaya. São Paulo: Cortez; Brasília: Unesco, 2000b.

18. MORIN, Edgar. Cultura de massas no século XX Necrose. Vol. 2. Tradução de Agenor Soares Santos. RJ: Forense, 2006.

19. MORIN, Edgar. Diário da China. Tradução de Edgard de Assis Carvalho. Porto Alegre, Sulina, 2007.

20. MORIN, Edgar. O Ano Zero da Alemanha.Tradução de Edgard de Assis Carvalho e Mariza Perassi Bosco. Editora Sulina, Porto Alegre-RS, Brasil, 2009.

21. MORIN, Edgar. Meu caminho. Tradução de Edgard de Assis Carvalho e Mariza Perassi Bosco. Rio de Janeiro: Bertrand Brasil, 2010a.
22. MORIN, Edgar. Meus demônios. Tradução de Leneide Duarte e Clarice Meireles. $5^{\mathrm{a}}$ Ed. Rio de Janeiro: Bertrand Brasil, 2010b.

23. MORIN, Edgar. Em busca dos fundamentos perdidos. Textos sobre o marxismo. Tradução de Maria Lúcia Rodrigues e Salma Tannus. $2^{\mathrm{a}}$ Ed. Porto Alegre: Sulina: 2010c.

24. MORIN, Edgar. Cultura de massas no século XX Neurose. Vol. 1. 10 ed. Tradução de Maura Ribeiro Sardinha. Rio de Janeiro: Forense, 2011a.

25. MORIN, Edgar. O método 4: as ideias - habitat, vida, costumes, organização. Tradução de Juremir Machado da Silva. 6. ed. Porto Alegre: Sulina, $2011 \mathrm{~b}$.

26. MORIN, Edgar. Introdução ao pensamento complexo. Tradução Eliane Lisboa. $4^{a}$ Ed. Porto Alegre: Sulina, 2011c.

27. MORIN, Edgar. O método 6: ética. Tradução de Juremir Machado da Silva. 4. ed. Porto Alegre: Sulina, 2011c.

28. MORIN, Edgar. O método 3: o conhecimento do conhecimento. Tradução de Juremir Machado da Silva. 6. ed. Porto Alegre: Sulina, 2012a.

29. MORIN, Edgar. O método 5: a humanidade da humanidade. Tradução de Juremir Machado da Silva. 5. ed. Porto Alegre: Sulina, 2012b.

30. MORIN, Edgar. Diário da Califórnia. São Paulo: SESC/SP, 2012C.

31. MORIN, Edgar. Chorar, amar, rir, compreender. São Paulo: SESC/SP, 2012d.

32. MORIN, Edgar. Um ano sísifo. Tradução de Edgard de Assis Carvalho e Mariza Perassi Bosco. São Paulo: SESC/SP, 2012e.

33. MORIN, Edgar. Journal 1962-1987. Paris: Editions du Seuil, $2012 \mathrm{f}$.

34. MORIN, Edgar. Journal 1992-2010. Paris: Editions du Seuil, 2012g.

35. MORIN, Edgar. O método 1: a natureza da natureza. Tradução de llana Heineberg. 3. ed. Porto Alegre: Sulina, 2013.

36. MORIN, Edgar. O método 2: a vida da vida. Tradução de Marina Lobo, Simone Ceré e Tânia do Vale Tschiedel. 5. ed. Porto Alegre: Sulina, 2015a.

37. MORIN, Edgar. L'aventure de la Méthode. Paris: Éditions du Seuil, 2015b.

38. MORIN, Edgar. L'Île de Luna. Paris: Actes Sud, 2017.

39. MORIN, Edgar. Poésies du Métropolitain. Paris: Descartes e Cia., 2018.

40. MORIN, Edgar; LEFORT, Claude; CASTORIADIS, Cornelius. Maio de 68: a brecha. Organizado e traduzido por Anderson Lima da Silva e Martha Coletto Costa. São Paulo: Autonomia Literária: 2018.

41. NIETZSCHE, Friedrich. Para além do bem e do mal. Tradução, notas e posfácio Paulo César de Souza. São Paulo: Cia. das Letras, 2005. 
42. PAILLARD, Bernard. A sociologia do presente. In: PENA-VEGA, Alfredo; LAPIERRE, Nicole (Orgs). Edgar Morin em foco. São Paulo: Cortez, 2008.

43. ROGGERO, Pascal. Para uma sociologia após "O Método". In: PENA-VEGA, Alfredo; LAPIERRE, Nicole (Orgs). Edgar Morin em foco. São Paulo: Cortez, 2008.

44. TACUSSEL, Patrick. Uma virada pós-empirista nas ciências humanas francesas. Revistas Famecos. N. 18. Porto Alegre, 2002. 